\title{
Chromogranin A Measurement
}

National Cancer Institute

\section{Source}

National Cancer Institute. Chromogranin A Measurement. NCI Thesaurus. Code C122108.

The determination of the amount of chromogranin A present in a sample. 